\title{
Apert syndrome: A case report
}

\author{
Zehra Ileri' \\ Yasar Bedii Goyenc ${ }^{2}$
}

\section{ABSTRACT}

The purpose of this report is to present Apert syndrome patient by highlighting craniofacial characteristics and orthodontic approach to treatment.

The patient, a 16-day-old female and the second child of healthy parents, was admitted to our department with primary complaint of cleft palate. She had a cone-shaped calvarium, midface hypoplasia, syndactyly of the hands and feet, hypertelorism, proptosis and cleft palate. After taking maxillary impression, an acrylic appliance was applied to orientate the growing and enable the feeding.

A case with Apert syndrome undergoes the orthodontic treatment for a long time and also a multidisciplinary approach is essential to determine the best collaborative corrective plan for the deficiencies of the patient. (Eur J Dent 2012;6:110-113)

Keywords: Apert Syndrome, newborn infant, craniosynostosis

\section{INTRODUCTION}

Apert syndrome (acrocephalosyndactylia) is a developmental malformation characterized by craniosynostosis, a cone-shaped calvarium lacrocephalyl, hypertelorism, midface hypoplasia, pseudo cleft-palate, a parrot beak-shaped nose, pharyngeal attenuation, and syndactyly of the hands and feet. ${ }^{1-3}$ The inheritance of Apert's syndrome is autosomal dominant with the locus of a mutation of FGFR2 on chromosome 10q 110q2526). Suture progenitor cells with fibroblast growth

1 Department of Orthodontics Faculty of Dentistry, Selcuk University, Konya, TURKIYE,

2 Private Practice, Balıkesir, TURKIYE

Corresponding author: Dr. Zehra Ileri

Selçuk Üniversitesi, Diș Hekimliği Fakültesi, Ortodonti Anabilim Dalı, Kampüs, Konya, 42075 TURKIYE

Tel: $+90-332-2231174$

Fax: $+90-332-2410062$

Email: zehra.ileridgmail.com factor receptors (FGFR2) that have undergone a mutation cannot transduce signals from extracellular fibroblast growth factors (FGFs). Therefore, these cells do not receive the signal to produce the necessary fibrous material essential for a normal calvarial suture. ${ }^{3}$

Apert syndrome was first reported by Wheaton in 1894 and French pediatrician Eugene Apert published a series of nine cases in 1906.1,4 Most cases are sporadic, with an incidence of 1:160 000; however due to high infant mortality, the incidence in the general population is lower. Advanced male parental age has been consistently noted. ${ }^{5}$ During the course of the disease, growth and mental retardation can be observed. ${ }^{1,5}$

In Apert cases, the spheno-occipital and spheno-ethmoidal synchondroses and the fronto-ethmoidal suture fuse early, resulting in a severely 
shortened posterior cranial base and a relatively short anterior cranial base with a resultant hypoplastic midface. Consistent with the observation of midface hypoplasia, the maxilla also exhibits a transverse deficiency. ${ }^{3}$ The most readily observed malocclusions are a severe maxillary anterior open bite and a severely crowded and retrusive maxillary arch due to the constricted secondary palate. ${ }^{3}$ The maxillary alveolar arch is V-shaped. ${ }^{6}$ Due to the narrower maxillary arch, bilateral or unilateral posterior crossbite can be observed. ${ }^{4,7}$ Impactions, severe crowding of developing teeth within the alveolus, delayed eruption, thick gingiva, and sometimes supernumerary teeth or congenitally missing teeth are the hall marks of maxillary dental development in Apert patients. ${ }^{8}$ The nasopharyngeal and oropharyngeal attenuation cause Apert's individuals to become mouth breathers with a resultant anterior open bite. ${ }^{3}$

\section{CASE REPORT}

A 16-day-old female infant was admitted to the Department of Orthodontics of Selcuk University because of cleft palate. From her parents' history, there was no syndromic individual in the family. She was the second child from a normal mother's third pregnancy of a consanguineous marriage between cousins. The mother's first child had died due to respiratory failure. Apert syndrome was diagnosed by DNA analysis and physical examination in the medical faculty.

During extraoral examination of the infant, whose appearance was noted with defects, it was observed that he displayed a cone-shaped cal-

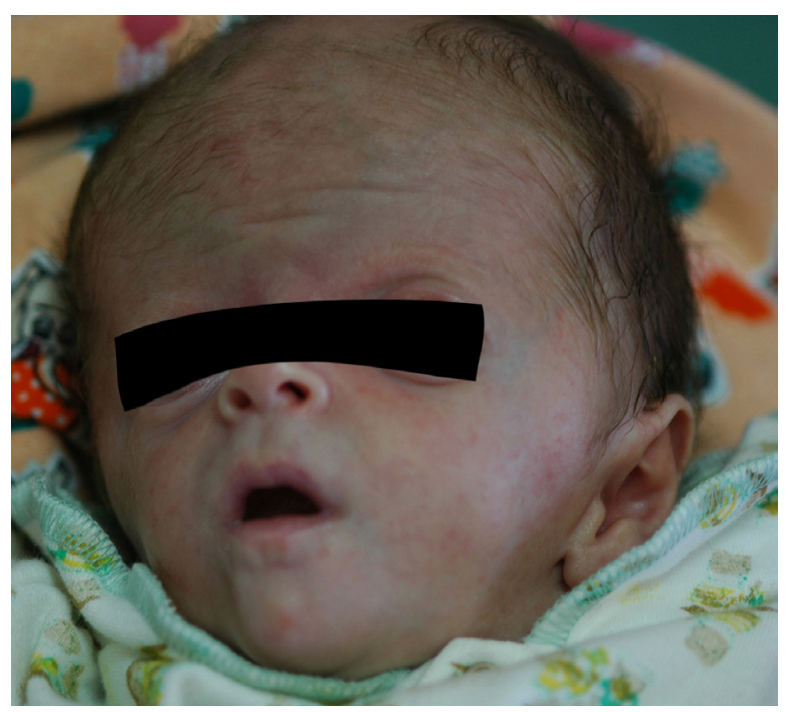

Figure 1. Extraoral appearance of the patient. varium, midface hypoplasia, hypertelorism, ocular proptosis, shallow orbits, down-slanting lateral canthi and palpebral fissures, a depressed nasal bridge, low-set ears, and syndactyly of the fingers and toes (excluding the thumbs) (Figures 1, 2, and 3). The baby had a dehydrated, weak appearance (Figure 1). Intraoral clinical examination revealed that upper and lower alveolar bases were normal, and a bifid uvula and secondary cleft palate (Figures 4, and 5) were presented.

The maxillary impression was taken by using silicon-based impression material (Zhermack SpA, Badia Polesine, Italyl and an orthodontic plaster model was obtained (Figures 4, and 5). After the cleft was covered with the wax, the acrylic appliance was made (Figure 6). Feeding the baby and orientating the growth was the goal of using this appliance for treatment. ${ }^{9}$

The appliance was worn on the patient, and the parents were instructed in full-time wear and cleaning procedures of the appliance. The parents was also informed about feeding the baby in a vertical position, using a nipple with a small hole through which milk flow rate was in the form of intermittent drops; therefore, the infants's perioral and buccal muscles would strengthen.

The baby was checked at intervals of six weeks for a period of six months (Figure 5). If it was necessary, the appliance was renewed during this period. When the baby was eight months, an operation was done to correct anomalies in the skull.

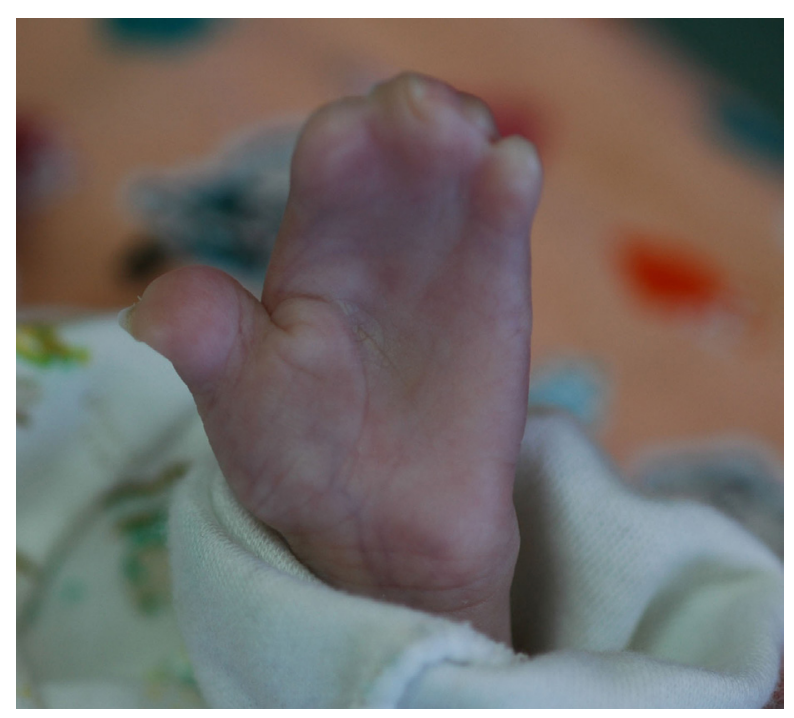

Figure 2. Syndactyly of the fingers. 


\section{DISCUSSION}

A silicon-based impression material was preferred to make the maxillary impression easier. During the impression, the head of infant is laid on the clinician's left knee. The baby's head is tilted backwards by holding the left knee forward. ${ }^{9}$

It is postulated that mutation in the FRFR2 gene has an effect on the mesenchymal development, which has an effect on tooth morphogenesis. ${ }^{10}$ Many oral manifestations can be attributed to the presence of this mutation.

Failure in the anteroposterior and downward growth of the maxilla causes the maxillary hypoplasia and a resultant contraction of nasopharyngeal airway. ${ }^{11}$ Therefore, one should pay attention

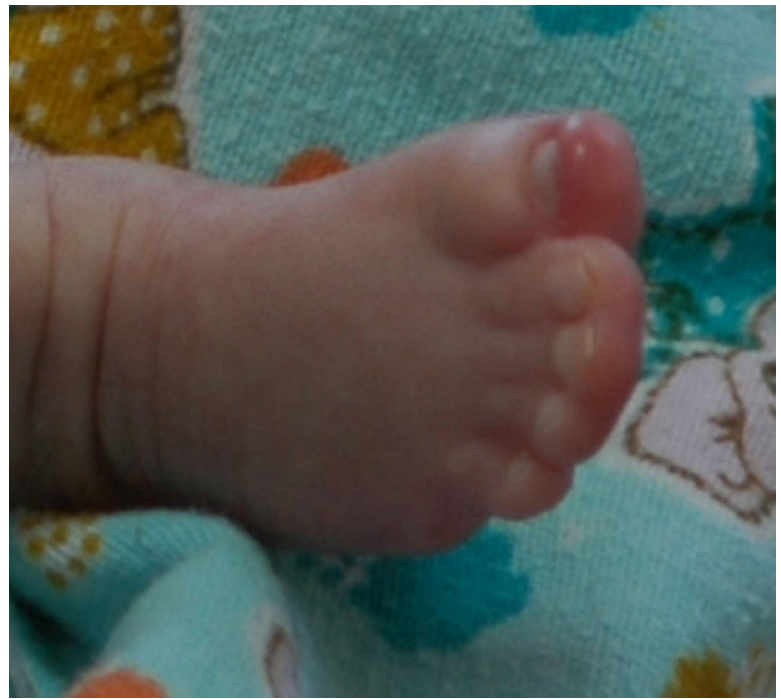

Figure 3. Syndactyly of the toes.

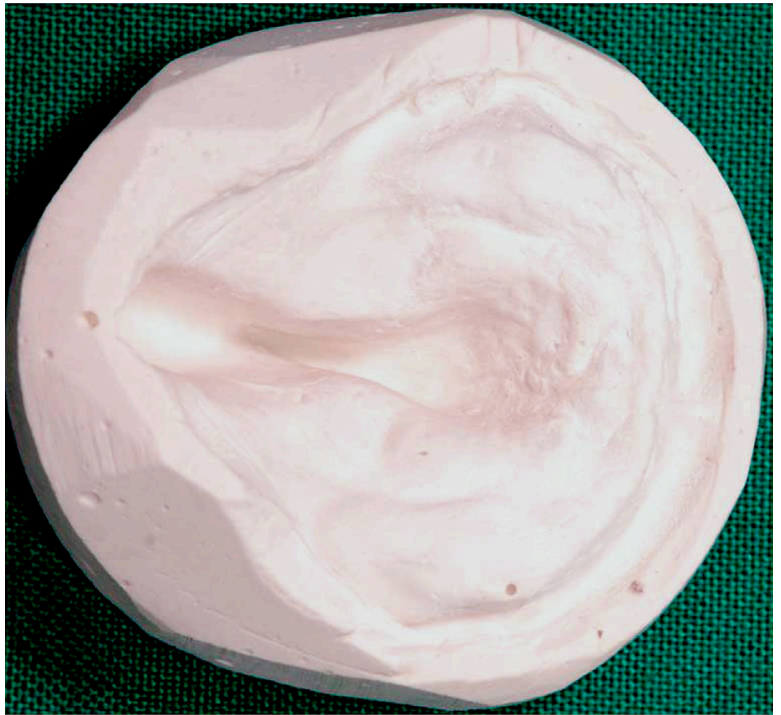

Figure 5. Plaster model of the 6-month-old baby. to obstructive sleep apne syndrome and premature death. ${ }^{1}$

In patients with Apert syndrome, severe skeletal Class III open bite malocclusion can be observed due to the maxillary deficiency and the inclination of the upper jaw. Therefore, it is usually necessary to add ortognathic surgery to the treatment plan. The infant is likely to suffer from oral hygiene problems during treatment.

For the patient with Apert syndrome, oral hygiene is as important as it is difficult. Hand deformities make it difficult to brush the teeth. The new generation of electric tooth brushes and fluoride mouth rinses may make the task easier. Professional care -including frequent dental examina-

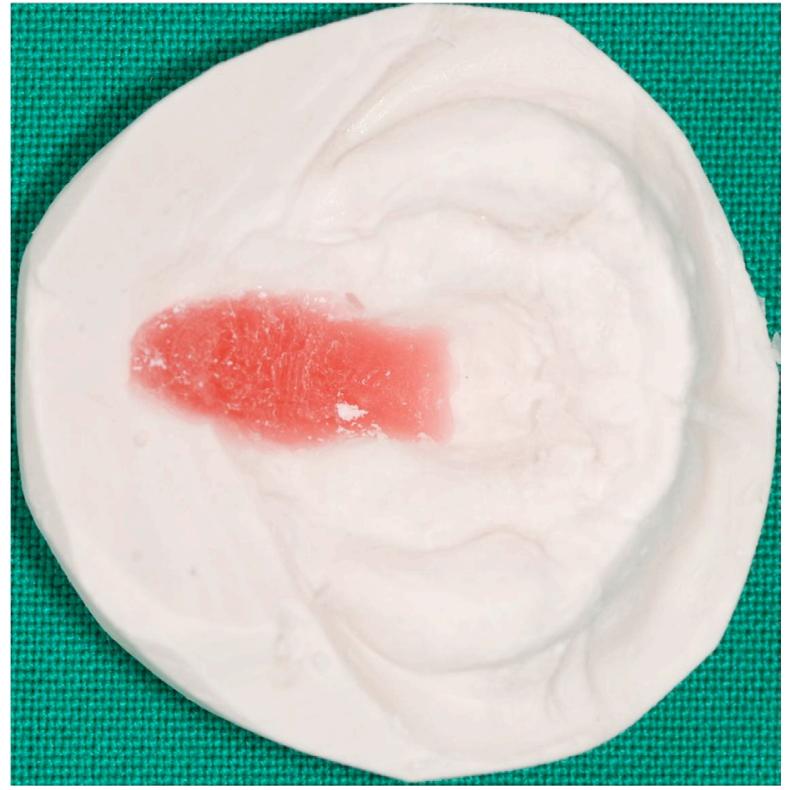

Figure 4. Plaster model of the 16-day-old y baby.

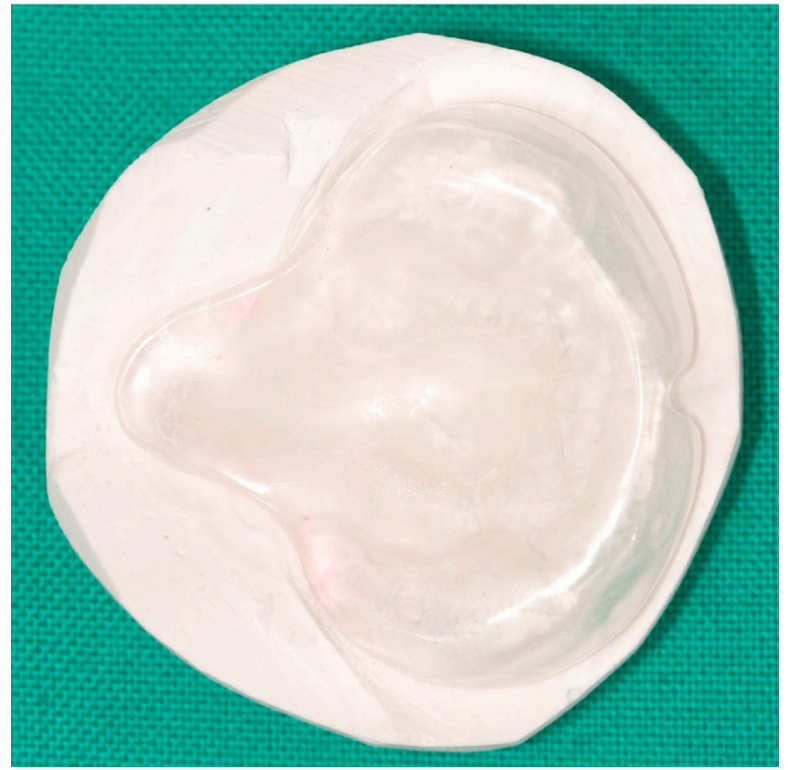

Figure 6. Hotz type of preoperative appliance. 
tions, oral hygiene prophylaxis, fluoride treatments, and dental sealants- are very important. ${ }^{4}$

Tosun and Sener's study showed that Apert syndrome was in parallel with $G_{6} P D$ deficiency. ${ }^{4}$ $G_{6} P D$ deficiency is an enzymatic hereditary disorder leading to hemolytic anemia as a result of red blood cell destruction. The main problem in $\mathrm{G}_{6} \mathrm{PD}$ deficiency is that hemolysis can be precipitated by a number of factors, such as oxidant drugs, eating fava beans, or intercurrent infection. Drugs that may induce hemolysis include sulphonamides, chloramphenicol, aspirin, acetaminophen, penicillin, and streptomycin. Therefore, the dentist must avoid drugs that may potentially induce hemolysis as result of $G_{6} P D$ deficiency. ${ }^{4}$

A significant proportion of patients with Apert syndrome has mental retardation. It is reported that $52 \%$ of the patients' IQ has been lower than 70. In these patients, significant social problems, speech difficulties, and attention deficit are noted. ${ }^{1}$

In Apert syndrome, definite diagnosis can be made by DNA analysis. Crouzon syndrome -another craniosynostosis disorder- is the result of the same gene mutation occurring in different locations. $^{1}$

\section{CONCLUSIONS}

This case demonstrates the general characteristic of a patient with Apert's syndrome. However, the treatment of these patients requires a multidisciplinary approach. Orthodontists can achieve an improvement in the patient's appearance and function of dentoskeletal structures by a combined orthodontic and orthognathic surgical treatment plan.

\section{REFERENCES}

1. Alp E, Alp H, Koc H, Ucar C, Cimen D. Apert syndrome. Türkiye Klinikleri J Pediatr 2007;16:264-268.

2. Canpolat M, Buyukayhan D, Gunes T, Akcakus M, Ozturk A, Kurtoglu S. Apert syndrome: A case report. Erciyes Medical Journal 2009;31:53-61.

3. Rynearson RD. Case Report: Orthodontic and dentofacial orthopedic considerations in Apert's syndrome. Angle Orthod 2000;70:247-252.

4. Tosun G, Sener Y. Apert syndrome with glucose-6-phosphate dehydrogenase deficiency: A case report. Int J Paediatr Dent 2006;16:218-221.
5. Hall RK. Facial dysmorphism and syndrome diagnosis. In: Pediatric orofacial medicine and pathology. 1st ed. London; Chapman \& Hall Inc, 1994:53.

6. Schudy FF. Treatment of Cruson's and Apert's syndromes. J Clin Orthod 1986;20:114-117.

7. Batra P, Duggal R, Hari P. Dentofacial characteristic in Apert syndrome: A case report. J Indian Soc Pedo Prev Dent 2002;20:118-123.

8. Ferraro NF. Dental, orthodontic, and oral/maxillofacial evalution and treatment in Apert syndrome. Clin Plast Surg $1991 ; 18: 291-307$.

9. Goyenc Y, Karadere I. Unilateral dudak damak yarıklı bebeklerde "Hotz" tipi pasif preoperatif apareyin etkileri. Turkish Journal of Orthodontics 1993;6:82-89.

10. Thesleff I, Vaahtokari A, Kettunen P, Aberg T. Epithelialmesenchymal signaling during tooth development. Connect Tissue Res 1995;32:9-15.

11. Moore MH. Upper airway obstruction in the syndromal craniosynostoses. Br J Plast Surg 1993;46:355-362. 